J. Biosci., Vol. 19, Number 4, October 1994, pp 503-509. (C) Printed in India.

\title{
A landscape approach to conservation of birds
}

\author{
R J RANJIT DANIELS* \\ Centre for Ecological Sciences, Indian Institute of Science, Bangalore 560 012, India \\ *Present address: M S Swaminathan Research Foundation, 3rd Cross Street, Taramani \\ Institutional Area, Madras 600 113, India
}

\begin{abstract}
Landscape ecology as a discipline in science is rather young. However its principles appear promising in outlining conservation strategies including a wide range of organisms, particularly birds. Birds due to their mobility use a variety of environmental resources, especially habitats. However, currently these habitats are only available in patches over most of the tropical world. Further whatever is left is under constant human pressure. This paper, therefore, addresses this problem and suggests means of dealing with it using the landscape approach as outlined by landscape ecology.

The landscape approach starts with the realization that patches of habitats are open and interact with one another. Corridors of trees along roads, hedgerows and canals in a landscape can aid in the movement of species. Hence the landscape approach considers patches of habitats as interacting elements in the large matrix of the landscape. The landscape approach also integrates concepts. It puts together often debated issues such as whether to preserve maximum species diversity, to maximize representativeness, or to preserve only the valuable species. Based on a case study of the Uttara Kannada district in Karnataka, these oft-opposing views and complications can be dealt with practically and synthesized into a conservation strategy for the diverse avifauna of the Western Ghats.
\end{abstract}

Keywords. Ecology; landscape approach; conservation; avifauna; Western Ghats.

\section{Introduction}

Birds contribute most significantly to the diversity of terrestrial vertebrates. Birds also have a special role in conservation as they not only help identify areas most worth saving, but also have the capacity to make conservation an "affair of the heart". Birds have even fostered international cooperation. Bird migration first convinced conservationists of the need to disregard frontiers, to protect birds all along their migratory routes. For example, cooperation in studies of avian migration was the stimulus to organize the first International Congress of Ornithology, perhaps the first international congress in biology. Besides, birds have to be protected for their own sake (Urquhart 1987).

As with any other group of organisms, the problem in conserving birds is the limited availability of habitats. This is particularly true in developing countries such as India where all available habitats have been and still are under constant human pressure. As a result some habitats have totally vanished while others remain as fragments. Such a condition has challenged conservationists, particularly those who insist on having only large contiguous habitats as natural reserves. However, since we are often left with only patches of remnant habitats, we have to adopt strategies that help us get the best out of these seemingly useless bits. It is here that landscape ecology finds the most application. 
Landscape has been defined as 'kilometers-wide area where a cluster of interacting stands or ecosystems is repeated in similar form'. A landscape is therefore an ecological unit with a distinguishable structure and landscape ecology can hence be considered as 'patch-work ecology'. It deals with patches; patches of different sizes, shapes and origin (Forman and Godron 1986; Noss 1983).

\section{Landscape approach}

A landscape approach to conservation of species demands an integration of ecological concepts. It starts with the realization that patches of habitats are interacting. All habitats are "open" and exchange energy, mineral nutrients and species. It thus makes the landscape mosaic a more important unit for study and management than individual, isolated habitat patches (Noss 1983). The landscape approach further teaches us to respect every 'useless' fragment in any landscape. For instance, corridors of trees along highways, hedgerows along cultivated areas, a channel, etc., can all aid the movement of species and thus make far apart patches interactive. Besides the movements of species, entire communities, can be dynamic too. Hence the landscape approach recommends dealing with an ecological mosaic of patches with continuously varying degrees of connectedness and recognises the importance of matrix and corridors to terrestrial habitat island dynamics (Noss 1983).

Managing a landscape also calls for assigning priorities to the elements (species or communities) involved. While some elements can exist only in large patches of habitats, many can thrive in the fragments. It is therefore essential to treat these separately instead of complicating the management plans by an equal emphasis on preserving all elements in a landscape. The landscape approach aims at preserving: (i) maximum species diversity, (ii) representativeness and (iii) species of high conservation value.

Species diversity has often been the prime attribute in conservation strategies. Sites have been evaluated merely by the number of species they contain. Species diversity is conventionally defined at three scales; $\alpha, \beta$ and $\gamma$. $\alpha$-diversity is the number of species within a single homogeneous habitat or community. $\beta$-diversity reflects the change in species composition along an environmental gradient or series of habitats. In simpler terms, it might be easier to consider $\alpha$ and $\beta$-diversities as within- and between habitat diversities. The total diversity in a larger area including more than one habitat such as in a landscape is called $\gamma$-diversity (Noss 1983). It is the $\gamma$-diversity that we ultimately aim at 'maximizing' in any landscape conservation plan.

Maximizing $\gamma$-diversity has however been criticized as dangerous when applied simplistically. Particularly in manipulated areas, a greater diversity may be the result of several introduced and non-native species (Noss 1983). Thus it has often led to arguments such as whether it is relevant to only conserve a number of species or try to ascertain the composition of the species (Diamond 1986).

Representativeness of species or communities has been emphasized as an alternative to maximizing diversity. For instance in the Biogeography Project of the Government of India, 1984; it was proposed to draw up a list of localities which are desirable to bring under protected area status in order to rectify the present deficiencies in representativeness (Rodgers and Panwar 1988). 
Preserving species based on some assigned values has also been much in focus currently. Though it has not been fully decided whether species are to be valued for 'their own sakes' or 'for our sakes', it is apparent that conservation evaluation and strategies are more effective if there are systems of attaching values to species. As a result, different ways of valuing species and/or communities have been proposed (The Nature Conservancy 1983; Usher 1986; Daniels et al 1991).

Since the three attributes discussed above are neither not always correlated not mutually exclusive of each other, a balanced strategy is needed. I have therefore tried to synthesize these within the norms of the landscape approach and outline a conservation strategy for the birds of the Western Ghats. The results presented are based on a five year case study in Uttara Kannada district (Daniels, 1989).

\section{Western Ghats}

The Western Ghats have one of the most complex and patchy landscapes in India. As a result of the topography and climatic gradient, the natural habitats vary from wet montane grasslands through a range of forests to dry rocky scrub. All these are interspersed with streams and marshes forming a natural mosaic of patches and corridors. Further interference by humans has fragmented the entire landscape creating several newer habitats including a variety of exotic species and considerably reducing the original extent of the natural habitats. Thus it is almost impossible to find homogeneous patches of habitats, especially evergreen forests, larger than a few square kilometers anywhere on the Western Ghats today.

The Western Ghats. have a rather diverse avifauna. There are 507 species of birds known from these hills and the adjacent narrow coastline. Of these 360 are residents; 15 being endemic. The number of resident species of birds on the Western Ghats is however lower when compared with other parts of the tropics, particularly the Neotropics. A comparable richness of birds has been reported from much smaller areas $\left(15 \mathrm{~km}^{2}\right)$ in Panama and Amazonia (Terborgh et al 1990). An analysis of the avifaunal composition of the Western Ghats suggests that it has much fewer representatives in all families of tropical forest birds than northeast India and the contiguous Southeast Asian mainland. The depauperate avifauna on the Western Ghats has been attributed to its prehistory and origin and to its being an island isolated from the rest of the tropical hills (Daniels et al 1992). Further, the species of birds have evolved under conditions of limited habitat availability that only $25 \%$ of the present avifauna are birds with some specialized habitat requirement; a few being specialists of evergreen forests (Daniels 1989).

Whether or not the avifaunal richness of the Western Ghats compares well with other tropical areas should not deter us from attempting to conserve these birds. The Western Ghats and the Eastern Himalayan foot hills support the last remnants of tropical forest birds in India. Therefore merely for the sake of 'representativeness' they ought to be conserved.

\section{A case study of Uttara Kannada's avifauna}

The Uttara Kannada district is located centrally on the Western $\left(13^{\circ} 55^{\prime}\right.$ to $15^{\circ} 32^{\prime}$ $\mathrm{N} ; 74^{\circ} 05^{\prime}$ to $\left.75^{\circ} 05^{\prime} \mathrm{E}\right)$. It belongs to the state of Karnataka in south India. This 
large landscape of $10,290 \mathrm{~km}$ is one of the most forested areas in peninsular India with a forest cover of $70 \%$. The forests include evergreen, semi-evergreen, moist and dry deciduous stands and a variety of secondary stages and monocultures of exotic trees such as eucalyptus, cashew, wattles and casuarina. It receives an average annual rainfall of $2500 \mathrm{~mm}$; mostly during the 5 rainy months (June-October). It is rather low in elevation with only a few hills exceeding $600 \mathrm{~m}$. Including the coastal and freshwater marshes, 21 major habitats have been identified within the district (Daniels 1989).

The avifauna of Uttara Kannada is fairly rich. Four hundred species are known from the district since it was first surveyed by Davidson in the 1890s (Davidson 1898a, b). Of these, 220 are residents (Daniels 1989). Thanks to the large landscape, and its great diversity of habitats and birds, Uttara Kannada turned out to be an ideal site for the study. Further, this district has a well documented past history of land use which helped in the analysis of the response of the avifauna to human caused habitat transformations during the past century. Interestingly, the results of this analysis showed that except for a few species of birds-those in the fringes of their geographical ranges within the district, the avifauna has largely remained the same for nearly 100 years (Daniels et al 1990). This surprising result and a complete inventory of gridwise $(5 \times 5 \mathrm{~km})$ bird-habitat distribution for the district are the basis for the conservation strategy outlined below.

\subsection{Maximizing avifaunal diversity}

If all species of birds in a landscape such as that of Uttara Kannada district are to be conserved, maximizing the $\gamma$-diversity should be the goal. Hague et al (1986) and Noss and Harris (1986) recommend the creation of a network of centres of diversity. These centres of diversity are called nodes. Each node is chosen in such a way that it is not only rich in species but also has the largest set of unique species. With proper links or corridors between the nodes, connectivity is increased. This arrangement renders the entire network to be an interacting system, thereby ensuring the continued existence of the entire avifauna within the landscape.

When such a procedure was followed, it turned out that by protecting 6 (out of 21) major habitats in the district, $80 \%$ of the avifauna can be maintained (Daniels 1989). However, as expected, an effort to maximize diversity had led to an overemphasis on protecting secondary and disturbed habitats such as urban centres, man-made reservoirs and beaches. The forest birds which are more characteristic to the Western Ghats were poorly represented (Daniels et al 1991).

\subsection{Preserving representativeness}

The Uttara Kannada district does not have any species of birds unique to its landscape. However, there are small populations of some of the little known and characteristic species of the Western Ghats. Examples are the Ceylon frogmouth, Wynaad laughing thrush, the great Indian hornbill, the Rufous-bellied hawk-eagle, and the Nilgiri wood pigeon. All these species were nowhere common. They are local and often exist as isolated populations; especially the frogmouth with its northernmost population in Uttara Kannada, totally isolated from the only other 
population which is widespread in Kerala. Similarly, the laughing thrush and hawk-eagle do not extend north much beyond Uttara Kannada. These birds are also not known from many parts of the Western Ghats between Uttara Kannada and Kerala. All the species mentioned above also happen to be birds of the evergreen forests. Thus a careful selection of patches of evergreen forests within the district can only ensure the survival of these species.

\subsection{Preserving the valuable bird species}

There are various ways of assigning conservation values to species. While some have been criticized as anthropocentric, others are widely accepted by conservationists. Valuing species by endemism, habitat specialization, taxonomic uniqueness and degree of endangerment has been more popular among those attributes generally accepted. Assigning numerical conservation values under these 4 attributes to each species of bird in the Western Ghats has helped assess localities in Uttara Kannada district by their value of birds. Thus when the 4 attributes were considered equally important and sites of conservation interest selected accordingly, the result suggested that by preserving 18 localities (out of the 107 surveyed) representing 5 major habitats, $75 \%$ of the district's avifauna can be protected. These include all the valuable birds of the district; the most important habitats of conservation interest being evergreen forests and marshes (Daniels et al 1991).

\section{A synthesis}

The case study of Uttara Kannada district discussed above has proved to be a most instructive object lesson in conservation planning. It however does not try to deal with issues such as whether preserve a single large area or several small patches (Simberloff and Abele 1984; Willis 1984). On the contrary if we agree with the statement that 'all parks and preserves are too small to protect their biological diversity', then we are forced to make compromises (Schonewald-Cox and Bayless 1986). Noss (1983) feels that larger reserves are easier to maintain. But how large should a preserve be for it to be considered large (Rafe et al 1985)? These issues are probably never resolvable. Therefore instead of complicating matters further let us consider the following situation.

In the Uttara Kannada district, evergreen-semievergreen forests are spread over approximately $65 \%$ of the land. The next important and very different habitat, i.e., the marsh, is more scattered and patchy. However, it is estimated that in about $30 \%$ of the district, there can be at least one marsh not less than $50 \times 50 \mathrm{~m}$ within every $25 \mathrm{~km}^{2}$ (Daniels 1989). If the largest available patches of these two habitats are preserved around the nodes identified, a major fraction of the district's avifauna and valuable species are preserved. Other nodes including beaches and scrub together cover almost all the species of birds in the district (figure 1). A selection of many smaller patches (less than a hectare or two) can add to the network. For instance, the sacred groves in the district are well-protected centres of diversity though often small. There are nevertheless species of thrushes, babblers and flycatchers breeding within these patches. Since these have been maintained by the local people for ages, no investment is needed to protect them further (Gadgil 1991). Most of the 


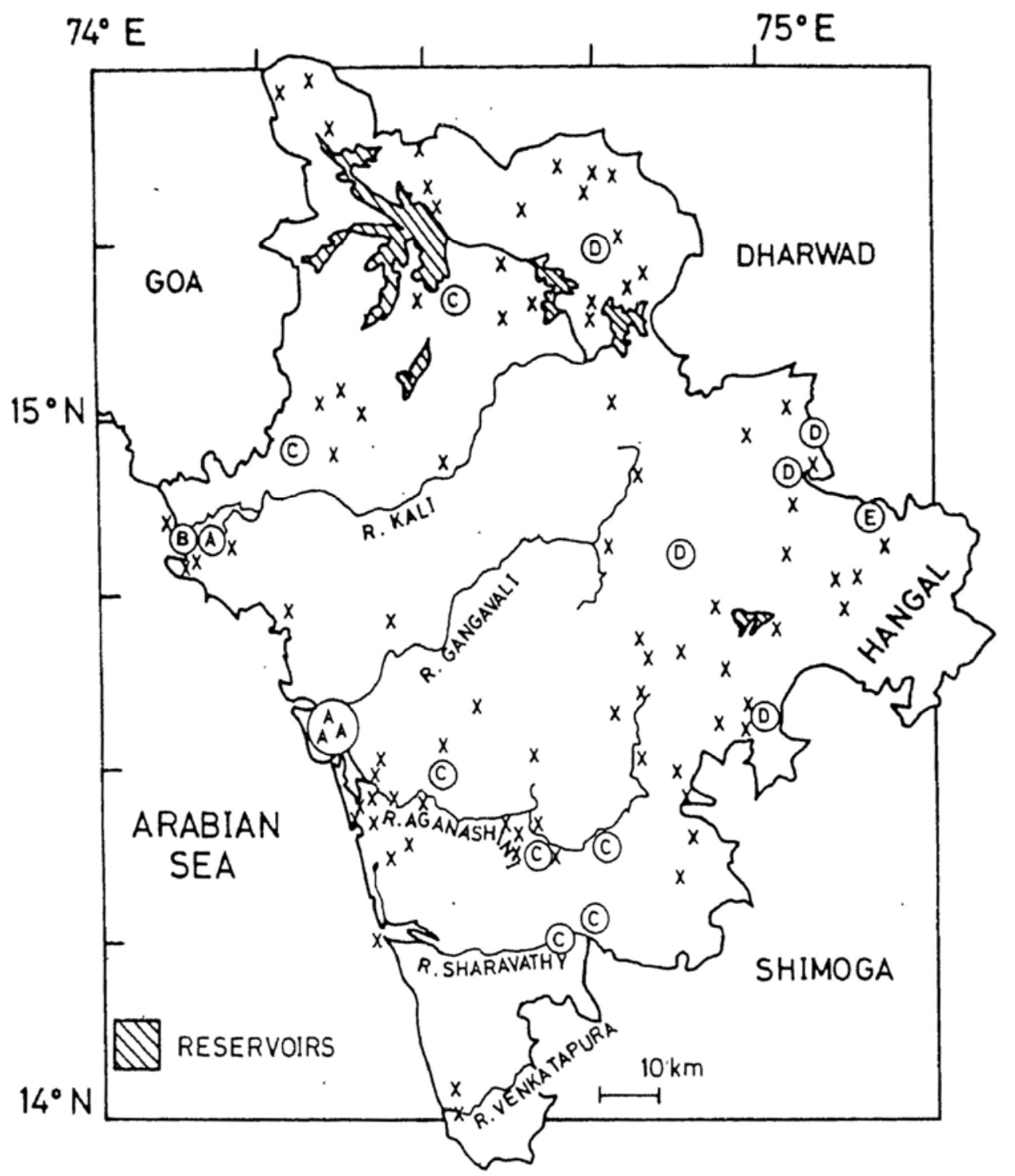
A : ESTUARY
B : $B E A C H$
C : EVERGREEN FOREST
$D:$ FRESH WATER MARSH
E : DRY SCRUB

Figure 1. Map of Uttara Kannada district with the adjacent Hangal taluk of Dharwad showing the localities of conservation interest (circles). " $\mathrm{X}$ " indicates all the sites surveyed. (After Daniels et al 1991)

secondary and man-made habitats including monocultures of teak and eucalyptus serve as corridors in Uttara Kannada. A careful utilization of these as links would make the network more complete and ensure survival of the district's diverse avifauna. 
The Uttara Kannada district is just one of the several districts in the Western Ghats. A similar approach to the conservation of birds in more parts of the Western Ghats, would help prevent loss of bird species in the long run. It is also hoped that this case study will be a model all over the country.

\section{Acknowledgement}

This study was funded partly by the Department of Environment, New Delhi.

\section{References}

Daniels R J R 1989 A conservation strategy for the birds of the Uttara Kannada district, Ph D Thesis, Indian Institute of Science, Bangalore

Daniels R J R, Joshi N V and Gadgil M 1990 Changes in the bird fauna of Uttara Kannada, India, in relation to changes in land use over the past century; Biol, Conserv. 52 37-48

Daniels R J R, Hegde M, Joshi N V and Gadgil M 1991 On assigning conservation value; a case study from India; Conserv. Biol, 5 1-12

Daniels R J R, Joshi N V and Gadgil M 1992 On the relationship between bird species richness and woody plant species diversity in Uttara Kannada district of south India; Proc. Natl. Acad. Sci. USA 89 5311-5315

Davidson J 1898a Birds of North Kanara, part 1; J. Bombay Nat, Hist. Soc. 11 652-679

Davidson J 1898b Birds of North Kanara, part 2; J. Bombay Nat. Hist. Soc. 12 43-72

Diamond J M 1986 The design of a nature reserve system for Indonesian New Guinea; in Conservation biology (ed.) Michael E Soule (Sunderland: Sinauer Assoc. Inc.) pp 485-503

Forman R T T and Godron M 1986 Landscape ecology (New York: John Wiley)

Gadgil M 1991 Conserving India's biodiversity: the societal context; Evol. Trends Plants 5 3-8

Hague P, Terborgh J W, Winter B and Parkinson J 1986 Conservation priorities in the Philippine archipelago; Forktail 2 83-91

Noss R F 1983 A regional landscape approach to maintain diversity; BioScience 33 700-706

Noss R F and Harris L D 1986 Nodes, networks and MUMS: preserving diversity at all scales; Environ, Manag. 10 299-309

Rafe R W, Usher M B and Jeferson R G 1985 Birds on reserves; the influence of area and habitat on species richness; J. Appl. Ecol, 22 327-335

Rodgers W A and Panwar H S 1988 Planning a wildlife protected area network in India. (Dehra. Dun: Report of the Wildlife Institute of India)

Schonewald-Cox C M and Bayless J W 1986 The boundary model: a geographical analysis of design and conservation of nature reserves; Biol, Conserv, 38 305-322

Simberloff D and Abele L G 1984 Conservation and obfuscation: subdivision of reserves; Oikos 42 399-401

Terborgh J, Robinson S K, Parker III T A, Munn C A and Pierpont N 1990 Structure and organization of an Amazonian forest bird community; Ecol, Monogr, 60 213-238

The Nature Conservancy 1983 Natural heritage program operations manual, Virginia, USA

Urquhart T 1987 Save the birds: why bother?; New Sci, 2 55-58

Usher M B 1986, Wildlife conservation evaluation: attributes, criteria and values; in Wildlife conservation evaluation (ed.) Michael B Usher (London: Chapman and Hall) pp 3-44

Willis E O 1984 Conservation, subdivision of reserves and the anti-dismemberment hypothesis; Oikos 42 396-398 